practice. Secondly, attempts can be made to capture current thinking in documentary form. Annual business plans and longer term strategic direction statements are tangible expressions of the organisation's vision.

These manifestations of the organisational vision are complementary rather than interchangeable approaches. Too great a reliance on documents runs the risk of them being seen as "tablets of stone" and may stifle imagination. On the other hand, alone informal communication and "networking" can result in wasted effort through lack of coherence: the vision is overwhelmed by indiscriminate and uncoordinated brainstorming. Each practice will need to strike a balance between these contrasting approaches which suits its size, personnel, and management style.

\section{How do you know if you've still got it?}

We have suggested that the practice vision needs to be broadly defined and regularly refreshed. This can come about only if individuals invest time and effort in the process. To justify and sustain this investment the quality of the resulting vision needs to be monitored. So how does an organisation know if its vision continues to be sound? Surprisingly, the answer is straightforward: if vision guides the organisation's planning, then as the future unfolds there are numerous reference points against which the meaningfulness (strictly, the predictive validity) of the vision can be checked and appropriate adjustments made. Without careful monitoring of this kind the organisational vision will sooner or later fail, perhaps catastrophically. Failure will be evident in two ways: external change will hit the practice with little or no warning; and rigorous organisational audit will reveal that significant objectives are not being achieved.

The next time you get angry about a "bolt from the blue" in the form of a decision by the Department of Health, General Medical Services Committee, family health services authority, regional health authority, etc, ask yourself: Should I have anticipated this? If when judged honestly the answer is yes, then something is wrong with your organisational vision. If the answer is no, take stock of any implications and build into your strategic plan sufficient resilience to cope with the (very) occasional surprise.

1 Holy Bible. Genesis xxxvii, 5-11, xl-xli.

2 Stephens GG. The intellectual basis of family practice. $f$ Fam Pract 1975;2:423 3 McCormick J. The vision thing: try it, you'll like it. Business Month 1990;135 (May):66-9.

4 NHS Management Executive. Integrating primary and secondary health care. London: NHSME, 1991.

5 Spiegal N, Murphy E, Kinmonth AL, Ross F, Bain J, Coates R. Managing change in general practice: a step by step guide. $B M \mathcal{F}$ 1992;304:231-4.

(Accepted 17 May 1993)

\title{
Patients with fatigue in general practice: a prospective study
}

\author{
Leone Ridsdale, Alison Evans, William Jerrett, Sundhiya Mandalia, Kay Osler, Hita Vora
}

Department of General Practice, United Medical and Dental Schools of Guy's and St Thomas's Hospitals, London SE11 6SP

Leone Ridsdale, senior lecturer in general practice Sundhiya Mandalia, assistant statistician in public health medicine

Hita Vora, research assistant in public health medicine

Department of General Practice, University of Leeds, Clinical Sciences Building, St James's

Hospital, Leeds LS9 7TF Alison Evans, lecturer in general practice

Old School Surgery, Pontyclun, Mid Glamorgan, Wales William Jerrett, general practitioner

The Surgery, Leiston, Suffolk IP16 4ES Kay Osler, general practitioner

Correspondence to: Dr Ridsdale.

BMF 1993;307:103-6

\section{Abstract}

Objective-To describe the characteristics of patients attending their general practitioners and complaining of fatigue or being "tired all the time."

Design-Prospective study of cohort aged 16 years and older with follow up at two weeks and by questionnaires at two and six months.

Subjects-220 patients (164 women) with mean age 43 years and an age-sex matched comparison group.

Settings-Doctors and patients in four practices in Lancashire, Mid Glamorgan, Suffolk, and Surrey.

Main outcome measures-General clinical data, results from standard group of laboratory tests, fatigue questionnaire, and 12 item general health questionnaire.

Results-Over twice as many patients with fatigue had high scores on the health questionnaire compared with the comparison group $(156(75 \%) v 69$ $(34 \%))$. Results of laboratory tests were abnormal and contributed to the diagnosis in 19 patients. 59 out of 102 patients who responded had high fatigue scores six months later. Patients with persistent fatigue were more likely to have a history of anxiety or depression and to have had fatigue for more than three months on entry to the study.

Conclusions-Women are particularly at risk of fatigue. The outcome is better if patients have had symptoms for three months or less or there is no history of emotional illness.

\section{Introduction}

Fatigue is a common subjective experience. Hannay reported on responses to interviews at home with patients from one practice and found that nearly a quarter of responders felt more tired or run down than usual. ${ }^{1}$ After respiratory symptoms this was the most common physical symptom described. Only a small proportion of those who experience fatigue as a problem come to the doctor. Morrell and Wale linked symptoms reported in women's diaries to their consultations in one practice and found a ratio of 400 episodes recorded to one consultation for fatigue. ${ }^{2}$

Fatigue may be the main complaint or a "supporting" symptom. Jerrett found about 75 per 1000 registered patients attended with fatigue as a presenting or supporting symptom in one year. ${ }^{3}$ Morrell found about 13 per 1000 registered patients presented with fatigue as their main complaint, and fewer than $2 \%$ were referred to secondary care. ${ }^{4}$ General practitioners can probably gain no useful information from research on fatigued patients in secondary or tertiary care.

During medical training clinical teaching is often focused on problems in which the diagnoses can be defined and there is some evidence from research to guide management. General practitioners often see patients with tiredness, but there is little scientific evidence from research done in primary care. ${ }^{5}$ In this context practitioners experience uncertainty, which may impair their confidence and relationships with patients.

We aimed to describe the characteristics of patients who consulted their general practitioners with a main complaint of fatigue or being tired all the time; compare their symptoms of fatigue reported on questionnaires with those reported by a comparison group matched for age and sex from the practice lists; and compare their symptoms of psychological distress reported on questionnaires with those of the comparison group. We also analysed the results of standard laboratory tests; measured the change in symptoms at intervals over a six month follow up period; and determined the characteristics on entry which predicted patients' fatigue symptoms six months later. 
Subjects and methods

Ethical committees approved the study in the four districts. Doctors recruited patients in separate practices in Lancashire, Mid Glamorgan, Suffolk, and Surrey. The practice populations lived in urban, suburban, semirural, and rural locations. The doctors' combined list sizes consisted of about 21420 patients in the middle of the year during which recruitment took place. Patients were recruited to the study if they were 16 years or older and their main reason for consulting was fatigue or synonyms like "being knackered, lethargic, run down, or tired all the time." When patients complained of more than one symptom, doctors asked what the main symptom was which led them to consult that day. The symptom must have been present for two weeks or more. Patients could be recruited only once, but the consultation for fatigue need not necessarily have been their first for this problem. The doctors in the study each carried out pilot trials in applying the entry criteria, and their performance was tested by using case vignettes. They received feedback before the study began and were reassessed during the course of the study year.

For each patient entering the study the doctor completed a structured data collection sheet which required the doctor to provide information from the patients' records about history of physical and psychological problems, and they arranged a standard group of laboratory tests. These measured haemoglobin concentration, white blood cell count, erythrocyte sedimentation rate or plasma viscosity, and concentrations of urea, electrolytes, thyroid stimulating hormone or thyroxine, and blood or urine glucose. Patients under 40 years old were also tested for glandular fever.

On entry to the study patients completed a questionnaire on duration of symptoms and a 14 item fatigue questionnaire which has been validated in general practice by Chalder et al. ${ }^{6}$ To measure the change in symptoms over the six months' follow up period we divided patients into two groups on the basis of a cut off score between 3 and 4 . Choice of threshold is to a certain extent arbitrary. It alters the sensitivity and specificity of the questionnaire when comparing results to a standard structured interview. A high sensitivity by using the questionnaire means that few true cases are missed but the false positive rates are high. Chalder et al found this cut off gave a sensitivity of $75.5 \%$ and a specificity of $74.5 \%$ when the questionnaire results were compared to results from the revised clinical interview schedule. ${ }^{\circ}$

On entry to the study patients also completed the 12 item general health questionnaire. ${ }^{7}$ This does not contain any questions about physical symptoms such as fatigue. The choice of threshold with the questionnaire in estimating the number of patients with psychological distress has the same implications as it does with the fatigue questionnaire. We used a threshold between 2 and 3, which Goldberg (personal communication) found to give a sensitivity of $86 \%$ and a specificity of $74.8 \%$ when he compared scores on a sample of patients by using the questionnaire with the scores from the composite international clinical interview.

When a patient was recruited a person of the same sex and the nearest younger by date of birth was selected from the same practice register. If this patient was found to have moved away or died the subsequent patient was chosen. This patient was sent the same questionnaires as those completed by fatigued patients on entry to the study.

All patients were asked to return for a follow up appointment two weeks later, and at this time they completed the fatigue and general health questionnaires a second time. Patients were also sent a fatigue and general health questionnaire to complete at eight weeks and six months.

Statistical analysis was by the test of proportions, the $\chi^{2}$ test for trend, and multilinear logistic regression. In some instances patients or doctors, or both, did not fill out all the items on the questionnaires. When cross tabulations were undertaken the denominator changed slightly, and so each denominator is stated for the data provided.

\section{Results}

RESPONSE RATES

Most patients were pleased to participate in the study as they thought the doctors were taking their symptoms seriously and might be able to help similar patients more as a consequence. Two patients refused outright, and doctors completed initial clinical data collection sheets on 220 patients. Two hundred and seven of these patients returned completed questionnaires after the consultation at which they entered the study. Two hundred and twenty age-sex matched patients were identified from the doctors' lists. Two hundred returned completed questionnaires. At two weeks $195(89 \%)$ of the study group returned for a follow up visit. At eight weeks $182(83 \%)$ returned their questionnaires, and at six months $172(78 \%)$ returned their questionnaires.

CHARACTERISTICS OF PATIENTS AND THE COMPARISON GROUP

Fifty six (25\%) of the study group were men and 164 $(75 \%)$ were women. The mean (range) age was 43 (17-88) years. Women patients with fatigue were over five times more likely to report that they had no paid work than women in the comparison group.

The patients' physical symptoms of fatigue and health questionnaires were initially scored in the same way as described by Wessely and Powell in a study of patients with chronic fatigue who attended the National Hospital for Nervous Disease and in whom a physical cause had not been found. ${ }^{8}$ The scores of the matched comparison group and for consulters with fatigue in primary care are shown in table I, together with the mean scores of patients reported by Wessely and Powell in tertiary care.

Two hundred and seven patients reported on the duration of their fatigue on entry. Thirty four $(16 \%)$ patients had had their symptoms for between two weeks and one month, $66(32 \%)$ for one to three months, $34(16 \%)$ for four to six months, and $74(36 \%)$ for longer than six months. There was a significant trend for those who on entry reported symptoms of longer duration to have had a previous episode of depression or anxiety recorded by the doctor (table II).

TABLE I-Mean scores ( $95 \%$ confidence intervals) for fatigue and on general health questionnaire in three groups

\begin{tabular}{|c|c|c|}
\hline Group & $\begin{array}{l}\text { Physical } \\
\text { fatigue }\end{array}$ & $\begin{array}{c}\text { General health } \\
\text { questionnaire }\end{array}$ \\
\hline $\begin{array}{l}\text { Matched comparison group } \\
\text { Patients with fatigue in general }\end{array}$ & $2.5(2.0$ to 3.0$)$ & $2.4(1.9$ to 2.8$)$ \\
\hline $\begin{array}{l}\text { practice } \\
\text { Tertiary care }\end{array}$ & $\begin{array}{l}8 \cdot 7(8 \cdot 2 \text { to } 9 \cdot 2) \\
11 \cdot 8(10 \cdot 8 \text { to } 13 \cdot 0)\end{array}$ & $\begin{array}{l}5 \cdot 2(4 \cdot 7 \text { to } 5 \cdot 7) \\
7 \cdot 0(5 \cdot 8 \text { to } 8 \cdot 1)\end{array}$ \\
\hline
\end{tabular}

TABLE II-Number of patients with fatigue and previous episode of depression or anxiety and duration of fatigue on entry

\begin{tabular}{lcc}
\hline Duration of fatigue & $\begin{array}{c}\text { No (\%) with previous episode of } \\
\text { depression or anxiety }\end{array}$ & $\begin{array}{c}\text { Total No of } \\
\text { patients }\end{array}$ \\
\hline < 1 Month & $5(15)$ & 33 \\
1-3 Months & $25(38)$ & 65 \\
4-6 Months & $12(36)$ & 33 \\
$>6$ Months & $34(46)$ & 74 \\
\hline
\end{tabular}

$\chi^{2}$ Test for trend 6.776, $d f=1, p=0.009$ 
Sixty nine $(33 \%)$ patients had one or more abnormal results on laboratory tests when the laboratories' criteria for abnormality were used (table III). One laboratory changed the method it used to test for glandular fever during the course of the study as it yielded too many positive values, so little confidence can be placed in this result. The doctors judged that an abnormal result was clinically important in 19 of 210 $(9 \%)$ patients. The clinical diagnoses were anaemia (eight), hypothyroidism (three), infection (three), glandular fever (three), diabetes (one), and carcinomatosis (one). In three additional cases the doctors were uncertain about the clinical importance of an abnormal result.

CHARACTERISTICS OF PATIENTS WHO DID AND DID NOT RESPOND AT FOLLOW UP

More women than men responded to questionnaires at six months but the difference was not significant. Patients who responded at six months were older (mean age 44 years; $95 \%$ confidence interval 42 to 47 ) than patients who did not respond $(38 ; 34$ to 41$)$. There was no significant difference in the mean fatigue scores on entry of those patients who failed to respond to questionnaires at six months.

CHANGE IN SYMPTOMS

All patients had self defined cases of fatigue on entry, but to describe the change in symptoms over the

TABLE III-Proportions of abnormal results of laboratory tests in patients with fatigue

\begin{tabular}{lr}
\hline Test & $\begin{array}{r}\text { No (\%) with } \\
\text { abnormal result }\end{array}$ \\
\hline Haemoglobin & $11 / 210(5)$ \\
White blood cell count & $9 / 210(4)$ \\
Erythrocyte sedimentation rate/plasma viscosity & $17 / 206(8)$ \\
Urea & $18 / 207(9)$ \\
Electrolytes & $5 / 206(2)$ \\
Glucose (serum or urine) & $4 / 206(2)$ \\
Thyroid stimulating hormone/thyroxine & $8 / 198(4)$ \\
Monospot & $8 / 83(10)$ \\
\hline
\end{tabular}

TABLE IV-Number (\%) of patients with high fatigue and general health questionnaire scores

\begin{tabular}{|c|c|c|}
\hline Patients & $\begin{array}{c}\text { High } \\
\text { fatigue score } \\
(4-14)\end{array}$ & $\begin{array}{c}\text { High } \\
\text { general health questionnaire score } \\
(3-12)\end{array}$ \\
\hline $\begin{array}{l}\text { Comparison group } \\
\text { Fatigue patients: }\end{array}$ & $71(35)$ & $69(34)$ \\
\hline On entry & $195(94)$ & $156(75)$ \\
\hline 2 Weeks & $158(81)$ & $123(63)$ \\
\hline 8 Weeks & $121(66)$ & $96(53)$ \\
\hline 6 Months & $102(59)$ & $80(47)$ \\
\hline
\end{tabular}

TABLE VI-Factors independently associated with high fatigue scores $(\geqslant 4)$ at six months according to linear logistic model

\begin{tabular}{|c|c|c|c|c|}
\hline Variable & $\begin{array}{l}\text { Odds } \\
\text { ratio* }\end{array}$ & $\begin{array}{c}95 \% \\
\text { Confidence } \\
\text { interval }\end{array}$ & $x^{2}$ & $\begin{array}{l}\text { Degrees } \\
\text { of } \\
\text { freedom }\end{array}$ \\
\hline Age (years) $§$ & 1 & 0.98 to 1.02 & 0.01 & 1 \\
\hline \multicolumn{5}{|l|}{ Sex: } \\
\hline Ment & 1 & & & \\
\hline Women & $0 \cdot 44$ & 0.19 to 1.02 & $3 \cdot 80$ & 1 \\
\hline \multicolumn{5}{|l|}{ Occupation: } \\
\hline Non-manual $\dagger$ & 1 & & & \\
\hline Manual & $1 \cdot 73$ & $0 \cdot 72$ to $4 \cdot 19$ & & \\
\hline Unemployed & $1 \cdot 04$ & 0.39 to 2.75 & & \\
\hline Others & 1.37 & 0.52 to 3.59 & 1.84 & 3 \\
\hline \multicolumn{5}{|c|}{ Previous episodes of anxiety/depression: } \\
\hline Not & 1 & & & \\
\hline Yes & 2.98 & 1.45 to 6.13 & $9 \cdot 27 \ddagger$ & 1 \\
\hline \multicolumn{5}{|c|}{ Duration of tiredness: } \\
\hline$\leqslant 3$ Months $\dagger$ & 1 & & & \\
\hline$>3$ Months & $2 \cdot 11$ & 1.08 to $4 \cdot 11$ & $4 \cdot 89 \ddagger$ & 1 \\
\hline
\end{tabular}

$\star$ Each adjusted for other factors in model.

†Baseline category.

$\neq \chi^{2}$ Statistic (for reduction in deviance) significant at $p \leqslant 0.05$.

AAnalysed as a continuous variable.

follow up period we divided the patients into two groups by using a cut off between 3 and 4 on the fatigue questionnaire $^{\circ}$ and between 2 and 3 on the general health questionnaire. ${ }^{7}$ An estimate of likely cases was made for patients on entry, at two weeks, eight weeks, and at six months on the basis of scores. This is shown in table IV with data on high scorers in the age-sex matched comparison group. By using this threshold more than half of the patients who consulted for fatigue had high symptom scores six months after entry to the study.

CHARACTERISTICS ASSOCIATED WITH HIGHER FATIGUE SCORES AT SIX MONTHS

Of the 220 patients who were initially recruited, 172 returned questionnaires at six months. Among this group $102(59 \%)$ had high fatigue scores (see table IV). The characteristics of the patients on entry were related to high fatigue scores ( 4 or more) at six months by using linear logistic regression analysis (table $\mathrm{V}$ ).

Age as a continuous variable was not associated with high fatigue scores at six months. Men were more likely to have high scores at six months, but the difference was not significant. When patients were grouped according to their occupation, those in manual occupations, particularly men, were more likely to have high fatigue scores after six months. The numbers in occupational subgroups were small, and this difference was not significant. The persistence of a high score on the fatigue questionnaire at six months was significantly associated with a history of fatigue of

TABLE V-Associations of variables with high fatigue scores ( $\geqslant 4$ ) at six months

\begin{tabular}{|c|c|c|c|c|c|c|c|c|}
\hline Variable & $\begin{array}{c}\text { No of } \\
\text { patients }\end{array}$ & $\begin{array}{c}\text { No }(\%) \text { of patients with } \\
\text { high fatigue scores }(\geqslant 4)\end{array}$ & $\begin{array}{l}\text { Unadjusted } \\
\text { odds ratio }\end{array}$ & $\begin{array}{c}95 \% \\
\text { Confidence interval }\end{array}$ & $x^{2}$ & $\begin{array}{l}\text { Degrees } \\
\text { of freedom }\end{array}$ & $\begin{array}{c}\text { Adjusted } \\
\text { odds ratio* }\end{array}$ & $\begin{array}{c}95 \% \\
\text { Confidence interval }\end{array}$ \\
\hline Age (years) & 172 & $102(59)$ & $1.01 t$ & 0.99 to 1.03 & 0.50 & 1 & & \\
\hline \multicolumn{9}{|l|}{ Sex: } \\
\hline Men‡ & 39 & $28(72)$ & 1 & & & & & \\
\hline Women & 133 & $74(56)$ & 0.49 & 0.23 to 1.07 & $3 \cdot 37$ & 1 & & \\
\hline \multicolumn{9}{|l|}{ Occupation: } \\
\hline Non-manual $\ddagger$ & 45 & $23(51)$ & 1 & & & & & \\
\hline Manual & 49 & $32(65)$ & 1.80 & 0.79 to $4 \cdot 12$ & & & & \\
\hline Unemployed & 34 & $20(59)$ & 1.37 & 0.56 to 3.35 & & & & \\
\hline Others (and no data) & 44 & $27(61)$ & 1.52 & 0.65 to 3.52 & $2 \cdot 06$ & 3 & & \\
\hline \multicolumn{9}{|c|}{$\begin{array}{l}\text { Previous episodes of anxiety, } \\
\text { or depression: }\end{array}$} \\
\hline Noł & 107 & $54(50)$ & 1 & & & & 1 & \\
\hline Yes & 65 & $48(74)$ & $2 \cdot 72$ & 1.42 to 5.41 & $9 \cdot 42 \$$ & 1 & $3 \cdot 15$ & 1.54 to 6.44 \\
\hline \multicolumn{9}{|l|}{ Duration of tiredness: } \\
\hline$\leqslant 3$ Months $\ddagger$ & 85 & $40(42)$ & 1 & & & & 1 & \\
\hline$>3$ Months & 87 & $60(69)$ & $2 \cdot 27$ & 1.22 to 4.23 & $6.86 \$$ & 1 & $2 \cdot 27$ & $1 \cdot 18$ to 4.34 \\
\hline \multicolumn{9}{|c|}{$\begin{array}{l}\text { General health questionnaire } \\
\text { scores on entry: }\end{array}$} \\
\hline$<3 \ddagger$ & 46 & $25(54)$ & 1 & & & & 1 & \\
\hline$\geqslant 3$ & 126 & $77(61)$ & $1 \cdot 32$ & 0.67 to 2.61 & 0.63 & 1 & 1.55 & 0.76 to $3 \cdot 17$ \\
\hline
\end{tabular}

*Adjusted for age, sex, occupation. 


\section{Practice implications}

- General practitioners manage $98 \%$ of patients who present with fatigue, and refer less than $2 \%$ to specialists

- This study shows that three quarters of patients with fatigue also have symptoms of emotional distress; $9 \%$ had a physical illness

- $59 \%$ of patients still had high fatigue symptom scores six months later

- History of anxiety or depression increased threefold by the risk of fatigue symptoms persisting over six months

three months or more on entry and with a history of anxiety or depression. High score on the general health questionnaire (of 3 or more) at entry was not associated with high fatigue scores six months later

As age, sex, and occupation might a priori be expected to be confounded with the other effects of interest, they were retained in the multiple logistic model used to assess the independent effects (table VI). A history of depression or anxiety on entry and a duration of fatigue of more than three months were independently associated with high fatigue scores at six months.

\section{Discussion}

In our study women were three times more likely to consult with fatigue, and when compared to the age-sex matched group they were more likely not to be in paid employment. A history of psychological disturbance was positively associated with the duration of fatigue before entry to the study. Patients with fatigue as a main symptom were more than twice as likely to report psychological symptoms above a threshold level as those in the comparison group. From this evidence we suggest that doctors need to consider and open up a discussion of psychosocial issues when patients present with tiredness.

One third of patients consulting for fatigue had a blood test which yielded abnormal results when the laboratories' own criteria were used. Except for three tests, the prevalence of individual abnormal results was compatible with a 95\% normal range. The doctors judged that laboratory abnormalities were clinically important in $19(9 \%)$ patients and treated them in the usual way. This proportion of abnormalities was higher than that reported in patients with chronic fatigue $^{9}$ and underlines the importance of vigilance for physical as well as psychosocial causes. The fact that common physical causes of fatigue have been identified and treated may conrtribute to the low yield of laboratory tests when patients with chronic fatigue are investigated by specialists.

Almost $40 \%$ of patients consulting for fatigue had low fatigue scores six months later, the rest still had high scores. This persistence of symptoms has been reported in North America. ${ }^{1011}$ A positive history of anxiety or depression and a longer duration of fatigue on entry were each predictors of poor outcome at six months. Knowing what to expect may help doctors and patients understand and come to terms with the problem. It is therefore worth inquiring about the duration of symptoms and noting the psychiatric history before discussing the prognosis. A short duration of symptoms and no history of anxiety or depression make the prognosis better.

We thank the Scientific Foundation Board of the Royal College of General Practitioners for funding this study and Professor D C Morrell, Dr S Wessely, Miss S Chinn, and many patients and colleagues for their help.

Hannay DR. Symptom prevalence in the community. $f R$ Coll Gen Pract 1978;28:492-9.

2 Morrell DC, Wale CJ. Symptoms perceived and recorded by patients. $f R \mathrm{Coll}$ Gen Pract 1976;26:398-403.

3 Jerrett WA. Lethargy in general practice. Practitioner 1981:4:731-7.

4 Morrell DC. Symptom interpretation in general practice. $7 \mathrm{R}$ Coll Gen Pract 1972;22:295-309.

5 Ridsdale L. Tired all the time. BMf 1991;303:1490-1.

6 Chalder T, Berelowitz G, Pawlikowska T, Watts L Wessely S, Wright D, et al. Development of a fatigue scale. I Psychosom Res 1993;37:147-53

et al. Development of a fatigue scale. $\mathcal{F}$ Psychosom Res 1993;37:147-53.
goldberg D, Williams P. A user's guide to the general health questionnaire. Goldberg D, Williams P. A user's guide to the general
Windsor: NFER-Nelson Publishing Company, 1988.

Windsor: NFER-Nelson Publishing Company, 1988.
8 Wessely S, Powell R. Fatigue syndromes: a comparison of chronic "postviral" fatigue with neuromuscular and affective disorders. I Neurol Neurosur Psychiatry 1989;52:940-8.

9 Valdini A, Steinhardt S, Feldman E. Usefulness of laboratory tests in investigating chronic fatigue in adults. Fam Pract 1989;6:286-91.

10 Cathebras PJ, Robbins JM, Kirmayer LJ, Hayton BH. Fatigue in primary care. f Gen Intern Med 1992;7:276-86.

11 Valdini OF, Steinhardt S, Valicenti J, Jaffe A. A one-year follow-up of fatigued patients. I Fam Pract 1988;26:33-8.

(Accepted 13 May 1993)

\section{Maintaining dignity above all}

In the days when a junior partner waited 10 years for equality and was given the unattractive jobs my partner insisted that I apply for a job that no one else wanted to bring a little more money into the practice. This was for a medical officer in a council run home for 39 elderly, mentally infirm residents.

The home had a container in which visitors left old clothes that might fit the residents, most of whom slept in chairs facing a poorly tuned television. Medication was handed out as an unthinking routine. The morale of the nurses was low, and they seemed incapable of behavioural analysis, relieving their dissatisfaction by verbal abuse. I found this regimented environment and negative work attitudes intolerable until one day a head nurse, made desperate by staff shortages, asked me to look at a new resident who took half an hour longer than the others over her meals and made a terrible mess. She was 69 , had been unable to cope living alone, and had been admitted by a social worker.

Examination showed an obese woman, with coarse features, thin hair, deep voice, and a tremor. Thyroid failure was diagnosed, confirmed, and replacement treatment begun. It was clear later that she had Parkinson's disease, and she responded well to anticholinergics in the days before levodopa. Ten weeks later she was once more doing the daily crossword and asked to go home. This was impossible because her house had been sold.

The effect of this on me was electric. The director of social services agreed with me that no admission should take place without prior medical assessment, and that all residents should wear their own clothes in order to maintain their individuality. An occupational therapist was engaged to encourage handicrafts. Finally, on my weekly visit I saw patients in the office with two nurses present, helping them to understand, for instance, that an old man who urinated against the wall was simply indicating that he did not know where the facilities were. Within a month I had reduced the drug bill by $£ 250$ with noticeable patient benefit. I decided then that care of the elderly was the most challenging and interesting feature of general practice.-KEITH THOMPSON is a retired general practitioner in Croydon

We are delighted to receive submissions of up to 600 words on $A$ paper (or patient or book) that changed my practice, $A$ memorable patient, The one message I would like to leave behind, or related topics. 